\title{
O caráter simbólico e prático da formação permanente para professores ${ }^{1}$
}

\author{
Symbolic and practical aspects of \\ permanent education for teachers
}

\section{Maria da Conceição Carrilho de Aguiar}

Professora adjunta do Departamento de Administração Escolare Planejamento Educacional e do Programa de Pós-Graduação / Núcleo de Formação de Professores e Prática Pedagógica do Centro de Educação da Universidade Federal de Pernambuco (UFPE), Recife, PE - Brasil, e-mail: aguiarcarrilho1309@oi.com.br

\section{Resumo}

Este estudo traz uma discussão sobre a formação permanente de professores. Trata-se de uma pesquisa de cunho qualitativo, com enfoque na teoria das representações sociais, e teve como objetivo compreender o que pensam e o que sugerem os professores sobre formação permanente. Para captar esses sentidos, foi aplicado um questionário a sessenta e dois (62) professores que lecionam desde educação básica ao ensino superior

\footnotetext{
${ }^{1}$ Texto apresentado no GT 8 da 32a Reunião Anual da ANPEd, Caxambu, out. 2008.
} 
nas redes pública e privada. As respostas às questões propostas foram analisadas com o apoio do software ALCESTER, cuja função é filtrar o essencial da mensagem contida em um texto. As análises apontam que as ações de formação não devem ser planejadas de forma isolada, uma vez que os professores são sujeitos ativos desse processo de construção pessoal e profissional. As representações sociais são, pois, um misto das ideias e crenças que os professores acumularam sobre o trabalho que desenvolvem e a formação permanente que buscam e que recebem, associam-se ao sentimento e à consciência de pertencerem a um grupo, de serem profissionais que interagem com o meio e os outros. Este estudo vem, portanto, confirmar a relevância da teoria das representações sociais como ferramenta apropriada para compreender os objetos educacionais como um todo e a formação dos professores, em particular.

Palavras-chave: Professor. Formação permanente. Significados.

\section{Abstract}

This study presents a discussion about permanent education for teachers. It is a qualitative research that focused on the social representations theory, aiming at understanding what teachers think and suggest about permanent education. In order to achieve this, we had sixty two (62) teachers from elementary school, high school and college and universities, public and private, answer a questionnaire. Their answers were analyzed with the support of the software ALCESTER, which filters a text to obtain its central meaning. The analyses indicate that permanent education initiatives must not be isolatedly planned since the teachers are active subjects in this personal and professional process construction. The social representations are a mix of ideas and beliefs that the teachers have accumulated about both the work that they do and the continuing education that they need and actually get, and are associated to the feelings and awareness they have of belonging to $a$ group as professionals that interact with others and with the environment. This study corroborates the importance of the social representations theory as an appropriate instrument to understand the educational objects as a whole and teachers' permanent education initiatives in particular.

Keywords: Teacher. Permanent education. Meanings. 


\section{Introdução}

\section{Formação permanente: os lugares sociais das relações concretas}

A intenção deste artigo é trazer algumas reflexões em torno da formação permanente diante do atual contexto das políticas de formação. Nessa perspectiva, compreende-se a importância da reflexão sobre a educação brasileira na atualidade, em que a precariedade, as dificuldades e os problemas estão colocados, tanto em um projeto social e político, que exclui ealiena, como também em práticas educacionais "ingênuas" e, muitas vezes, reprodutivistas, que não percebem os professores como sujeitos historicamente situados, condição necessária para a compreensão e transformação desse contexto.

De maneira geral, Freire (1997) recomenda que, para ensinar, o professor precisa ter competência pessoal, técnica e política que contemple qualidades, como: cuidado com o método e a metodologia que utiliza durante o desenvolvimento de sua atividade e com a estética e ética da sua função; pesquisar o objeto de ensino; respeitar os saberes dos estudantes; aceitar o risco de aderir ao que é novo e respeitar qualquer forma de discriminação; refletir criticamente na e sobre a prática; reconhecer e assumir que os conhecimentos são históricos, culturais e transitórios.

Nesta pesquisa, buscou-se, com um grupo de professores em processo de formação permanente, responder à seguinte questão: o que pensam e o que sugerem os professores sobre formação permanente?

\section{Formação permanente: recuperando o debate}

$\mathrm{Na}$ literatura especializada, há um fértil debate sobre o papel da efetivação da formação permanente de professores e suas implicações para o desempenho profissional e à aplicabilidade dos saberes aos contextos de trabalho. Chega-se a admitir que as ações de formação serão mais eficazes à medida que responderem às necessidades individuais dos professores.

A este respeito, Pacheco (1997) defende que a formação passa pelo exercício de compreender o outro nas suas semelhanças e diferenças e no processo de escuta e troca. Não supondo a diferença em termos de saberesinformação, mas também em saberes de experiências diversas. E esses saberes 
situam-se em função das áreas disciplinares, da sociedade na qual estão inseridos, da classe social à qual pertencem, dos interesses de cada um, da idade, do sexo, etc, construindo mentalidades e formas de estar na vida diferenciadas.

Dessa forma, na formação, a desestruturação e o questionamento de preconceitos constituem uma tarefa importante, muito embora situem-se num campo de sensibilidades muito fortes, uma vez que o preconceito é uma peça de um conjunto bem estruturado que possibilita ler o mundo e decifrar quem é ele e quem são os outros. Questioná-lo é pôr em desequilíbrio essa leitura. A procura de novos equilíbrios pode produzir a mudança ou levar a uma maior rigidez. Tudo depende não só de uma lógica do raciocínio, como também de uma lógica dos sentidos. Para romper ou não com valores, crenças e certezas construídas ao longo de uma trajetória de vida.

Magalhães (2000) sugere que a formação poderia ter uma dimensão mais sociológica e menos psicologizante, uma vez que remete para as questões ligadas ao desempenho individual, quando a investigação vem apontando que os constrangimentos parecem ser mais de ordem social e cultural. Isso implicaria o não reconhecimento dos alunos concretos que os professores têm perante si e que está na base do discurso desqualificador, tem a ver com o fato de a formação não se dimensionar também em termos sociológicos, mas de sensibilização sociológica e antropológica dos contextos em que a educação escolar acontece.

A formação permanente, na concepção de Placco e Silva (2002, p. 26-27), é entendida:

[...] como um processo complexo e multideterminado que ganha materialidade, em múltiplos espaços/atividades, não se restringindo a cursos e/ou treinamentos, e que favorece a apropriação de conhecimentos, estimula a busca de outros saberes e introduz uma fecunda inquietação contínua com o já conhecido, motivando viver a docência, em toda a sua imponderabilidade, surpresa, criação e dialética com o novo.

Há um certo consenso de que o espaço relativo à formação permanente, na atualidade, não se prende ao professor de forma individual, mas ao professor em todo o seu contexto coletivo, profissional e organizacional.

Para Nóvoa (1991), a formação permanente precisa considerar o desenvolvimento profissional dos professores, possibilitando a autonomia 
contextualizada da profissão e valorizando a preparação de professores que reflitam e assumam as responsabilidades profissionais, participando na implementação das políticas educacionais.

A mudança no contexto da formação permanente é concebida em ligação com vários setores e áreas de investigação, como afirma Nóvoa (1991, p. 18):

a formação não se faz antes da mudança, faz-se durante, produz-se nesse esforço de inovação e de procura aqui e agora dos melhores percursos para a transformação da escola. É esta perspectiva ecológica de mudança interactiva dos profissionais e dos contextos que dá um novo sentido às práticas da formação centradas nas escolas.

Assim sendo, para que ocorra a mudança educacional é preciso que haja conexão com os professores, com sua formação e com a transformação das práticas pedagógicas da sala de aula. Contudo, no contexto atual não se inova sem promover mudanças tanto nas organizações escolares quanto em seu funcionamento. Desse modo, falar de formação permanente de professores implica investir educacionalmente nos projetos escolares. A partir dessas considerações, o autor chama a atenção para as decisões no domínio educativo que vêm oscilando entre o nível excessivo global do macrossistema e o nível excessivo restrito da microssala de aula.

A formação permanente dos professores não pode desconhecer essa realidade, deve articular-se com o desenvolvimento das organizações escolares. O desafio está, portanto, em compreender a escola como um ambiente educativo, onde trabalhar e formar não sejam atividades isoladas, mas articuladas e inovadoras.

É nesse contexto que a formação permanente pode possibilitar práticas reflexivas, ajudando os professores a tomar consciência delas, compreendendo-as e elaborando formas de enfrentá-las. Para isso, é preciso integrar os conteúdos em situações da prática que coloquem problemas aos professores e lhes possibilitem experimentar soluções, possibilitando, dessa forma, ter a prática como referente direto para contrastar com os estudos teóricos e formar seus próprios conhecimentos e convicções.

A formação permanente é aqui entendida como um espaço de criação e incentivo às trocas de experiências entre os professores e professoras e estudantes, de modo que se implante uma cultura colaborativa. 
Não basta saber sobre as dificuldades da profissão, é preciso refletir sobre elas ebuscar soluções, de preferência, mediante ações coletivas. No contexto atual, o professor precisa se envolver com toda a estrutura organizacional da escola e a formação permanente pode possibilitar práticas reflexivas, ajudando os professores a tomar consciência das novas e difíceis condições de exercício da profissão, compreendendo-as e elaborando formas de enfrentá-las.

A formação precisa articular-se com o desempenho profissional do professor e as escolas como lugares de referência. E os programas de formação deverão ser estruturados em torno da resolução de problemas e de projetos de ação; o apoio às práticas de formação permanente deve estimular a apropriação pelos professores, individual e coletivamente, dos seus próprios processos de formação. O diálogo entre os professores é fundamental para consolidar saberes emergentes da prática profissional e sua formação que deve passar pela experimentação, pela inovação, pelo ensaio de novos modos de trabalho pedagógico. Como também para reflexão crítica sobre a sua utilização. Passando, ainda, por processos de investigação diretamente articulados com as práticas educativas. É preciso passar de uma investigação sobre os professores para uma investigação com e pelos professores.

Para Canário (1999), as expectativas quanto às potencialidades da formação, em sociedades que evoluíram de uma situação marcada pela estabilidade para outra marcada pelo avanço brutal das mudanças sociais e tecnológicas, ampliaram-se ao domínio da produção de mudanças, abrangendo vários setores da atividade social. A convicção nas virtudes da formação algumas vezes encarada como condição necessária e suficiente para o êxito de empreendimentos reformadores tem alimentado a convicção de que, para mudar a educação, a saúde, a economia, é preciso formar professores, médicos, enfermeiros e empresários.

Entretanto, a fase, marcada pela euforia, ocorre a partir de um sentimento de decepção que acompanha o crescimento da oferta de formação permanente, o que é comum a diferentes domínios da atividade social. Esta ineficácia, segundo Canário (1999), está ligada à persistência de modalidades escolarizadas de formação, consolidada numa lógica cumulativa das atividades de formação que tem subentendido uma perspectiva instrumental e adaptativa. "A perspectiva instrumental e adaptativa dos processos de formação fundamenta-se numa visão global do homem como entidade 'programável' que tem sustentado a idéia de que, com base na formação, seria possível criar um 'homem novo"' (CANÁRIO, 1999, p. 40). 
Contudo, esta perspectiva instrumental e adaptativa da formação traduz-se numa racionalização quer da formação, quer dos processos de mudanças que valorizam as dimensões técnicas, em detrimento das dimensões pessoais e sociais.

Vale salientar que a realidade social com a qual se articula o campo da formação profissional permanente é, no contexto atual, marcada pelo fenômeno da mobilidade social que modifica, de forma significativa, as relações entre formação e trabalho.

Diante do exposto, as mudanças enfrentadas pelos professores, nos dias atuais, manifestam-se numa complexidade difícil de administrar, porque não dependem somente deles, mas também das relações deles com os outros e com todo o contexto político, econômico e social. Como afirma Esteve (1995, p. 97):

a situação dos professores perante a mudança social é compatível à de um grupo de actores, vestidos com traje de determinada época, a quem sem prévio aviso se muda o cenário, em metade do palco, desenvolvendo um novo pano de fundo, no cenário anterior.

Na mesma linha de raciocínio, Coelho (2000, p. 25) acrescenta:

[...] a formação educativa que se vem impondo como a mais adequada ao conhecimento do mundo hoje é a que procura articular entre si determinadas áreas de saber, de maneira que cada uma ilumine as outras e seja, por sua vez, iluminada por elas. Adquirir cultura ('saberes essenciais') não significa acumular conhecimentos, mas sim organizá-los em torno de eixos de idéias, num determinado contexto que seja significativo para o sujeito. Nos rastros do pensamento complexo, todas as discussões que vêm sendo feitas em torno da 'crise do ensino' têm como base uma das premissas da psicologia cognitiva :sem estar integrado num contexto, nenhum saber tem valia, por mais sofisticado que seja, isto é, não provoca no sujeito o dinamismo interno que o levaria a interagir com outros saberes e ampliar o conhecimento inicial ou transformá-lo.

Caramelo, Terrasêca e Pacheco (1997) postulam que a dinâmica da formação ultrapassa o tempo e o espaço da instituição definida para a intervenção dos formadores, como também o cotidiano da vida de cada um é atravessado pelas aprendizagens realizadas nas e pelas sessões de formação, sendo transportadas para as suas vivências profissionais e 
de estudantes. Um processo paralelo é a tomada de consciência de que certas situações comuns podem constituir-se em situações informais de formação, capazes de serem transportadas para um espaço formal e serem reconhecidas.

Para isso, é necessário saber mais sobre as informações que os professores possuem, quais os dados que eles extraem do que veem e vivenciam no cotidiano da escola; isto deve ser construído e transformado em conteúdos da formação.

Amiguinho (1992) defende que uma formação na inovação tem lugar num processo não pela obtenção de saberes, mas pela produção de saberes, logo, a formação passa da esfera do consumo para a esfera da produção. Nesse sentido, considera a formação, enquanto processos inacabados, que pressupõe a interligação de atividades informacionais, atividades interativas e atividades produtivas.

\section{Representação Social como categoria de análise}

As Representações Sociais são teorias do senso comum que se elaboram coletivamente nas interações sociais, sujeito-sujeito e sujeitoinstituição, num determinado tempo, numa cultura e num espaço específico, na tentativa de tornar o estranho familiar e dar conta da realidade. É na interação que o sujeito elabora o conhecimento e vai se socializando, construindo valores e ideias que circulam na sociedade.

Para Moscovici (1978) e Jodelet (2001), as focalizações que os indivíduos fazem decorrem das condições materiais, e ideológicas, dos recursos educativos e dos interesses profissionais de cada indivíduo. São esses fatores que direcionam a focalização da Representação Social em aspectos isolados do objeto social. Cada sujeito pode focalizar aspectos distintos do objeto social, conforme sua experiência social e os interesses diversificados que possui sobre ele.

De acordo com Moscovici (1978), as Representações Sociais não somente guiam as ações, mas também remodelam e reconstituem os elementos do meio ambiente em que tais ações têm lugar, integrando-as em uma rede de relações na qual está vinculado o objeto, fornecendo as noções teóricas e os fundos de observação que tornam essas relações estáveis e eficazes. 
Assim, as Representações Sociais funcionam como um sistema de interpretação da realidade que orienta as relações dos indivíduos com o meio físico e social. Elas determinam os comportamentos e as práticas dos sujeitos. O sujeito, nas suas relações sociais e comunicativas, é, inevitavelmente, levado a tomar partido nessas relações.

Conforme Moscovici (1978), o sujeito aprende a elaborar, do seu modo, os conhecimentos científicos fora do espaço em que eles foram gerados, imbuindo-se do conteúdo e do estilo do pensamento que lhe representam. O surgimento de uma teoria ou de uma metodologia desconhecida tem sempre um impacto semelhante. A relação com a realidade, os valores hierarquizados e o peso relativo dos comportamentos, tudo isso é alterado. As normas são simultaneamente modificadas: o que era permitido revela-se proibido, o que era irrevogável parece revogável, e vice-versa.

Nessa perspectiva, o senso comum tem regras próprias, valores, crenças e segue uma lógica natural, não formal. Os grupos constroem verdades diferentes de acordo com o nível de informação que se tem; quando elaborada nas interações, torna o estranho familiar. Quando você absorve um novo objeto, modifica este objeto e os antigos são revistos. A representação social é dinâmica, pois novas informações recebidas a respeito de um objeto de conhecimento podem vir a provocar alterações na concepção anterior deste objeto. Ela possibilita justificar, a posteriori, tomadas de posição e de condutas do sujeito. Tem uma função identitária que possibilita definir identidades e salvaguardar as especificidades dos grupos. Em contraste com o conhecimento de senso comum, o conhecimento científico se constrói a partir de um problema, uma pergunta que se faz e se quer entender.

É uma forma de conhecimento da realidade em que se procura dominar a natureza e buscar explicação, apresentando características próprias. Ele reúne um conjunto de hipóteses, elaboradas a partir de possíveis respostas às perguntas, de modo que algumas dessas hipóteses sejam premissas e as outras as sucedam logicamente.

Para Moscovici (1978), uma representação produz e determina os comportamentos, levando o indivíduo à seleção de certos estímulos e fazendo emergir alguns significados às respostas dadas. Ela possui uma função característica da realidade da qual se conhece pela experiência adquirida e de cuja função a maioria dos indivíduos faz uso. 
As representações sociais não são homogêneas, pois são construídas a partir da diversidade dos grupos. Quando o sujeito se apropria do conhecimento do senso comum, os componentes ideológicos fazem parte dos valores de que as pessoas se apropriam. Jodelet (1984, p. 362) afirma: a marca social dos conteúdos ou dos processos de representação remete às condições e ao contexto dos quais emergem as representações, às comunicações pelas quais elas circulam, às funções que elas têm na interação com o mundo e com os outros.

Não sendo as representações sociais apenas opiniões, atitudes sobre ou imagem de, mas uma teoria articulada sobre um objeto, elas reconstituem os elementos do meio ambiente, integrando-o a uma rede de relações às quais está vinculado o seu objeto. Ou seja, o que diferencia as representações das noções de imagem, atitudes e opiniões são os vínculos entre os elementos do meio ambiente, articulados nos processos de interação em que se formam as representações.

Para Moscovici (1978), não admitir o poder criador de objetos, de eventos, de atividades representativas leva a acreditar que não existem relações entre o que está armazenado nas imagens e a capacidade de engendrar novas e surpreendentes combinações das quais a cultura e o senso comum são testemunhos cotidianos. Nesse processo de construção do conhecimento sobre o objeto, o indivíduo se constitui e, ao mesmo tempo, situa-se no universo social e material segundo a organização que ela se dê ou aceite do real.

Os postulados de Moscovici reforçam o valor da teoria como referencial para essa investigação, uma vez que, de acordo com este autor, os indivíduos em seus espaços de atuação, na interação com os outros indivíduos e com os instrumentos de trabalho, vão construindo seus conceitos, concepções, ideias e valores. Admite-se que com os professores não seria diferente, eles certamente têm ancorado essas representações.

A partir das indicações teóricas aqui apresentadas sobre a Teoria das Representações Sociais, podem-se conhecer o universo simbólico dos professores e a concepção de formação permanente.

\section{Percurso metodológico}

Este estudo traz uma discussão sobre a formação permanente de professores. É uma pesquisa de cunho qualitativo e apresenta como objetivo compreender o que pensam e o que sugerem os professores sobre formação permanente.

Rev. Diálogo Educ., Curitiba, v. 10, n. 30, p. 301-316, maio/ago. 2010 
Optou-se pela abordagem qualitativa, com enfoque nas representações sociais que os professores têm de formação permanente, o que estão pensando e vivendo no contexto da prática social e da representatividade construída por meio do conhecimento das experiências diversas.

Sabe-se que a realidade empírica, para Luna (1994, p. 31), é complexa, porém objetiva. Ela não traz em si ambiguidade. O homem individual é subjetivo pela incapacidade de separar o objeto da concepção que faz dele, em relação ao que vê do que imagina e, sobretudo, porque é incapaz de ler, na observação, o processo que determina um fenômeno particular momentâneo (mesmo porque dificilmente ele se evidenciaria nesta situação).

\section{Participantes}

Participaram da pesquisa sessenta e dois (62) professores, que trabalham nas várias redes (federal, estadual, municipal) e lecionam desde a educação básica ao ensino superior. $\mathrm{Na}$ ocasião da pesquisa, todos os participantes estavam matriculados em cursos de especialização (lato sensu) oferecidos por universidades e faculdades públicas e privadas. O grupo pesquisado encontra-se na faixa etária entre 23 e 57 anos, sendo 14 do sexo masculino e 48 do sexo feminino.

\section{O instrumento}

O questionário é um instrumento que pode ser definido como uma pergunta particular sobre determinada situação envolvendo indivíduos, com o objetivo de generalizar. Para tal, o pesquisador intervém apresentando questões, porém sem intenção clara de modificar a situação na qual atua enquanto pesquisador (GHIGLIONE; MATALON, 1997).

Nessa perspectiva, os discursos que constituem as respostas dadas às perguntas do questionário não são espontâneos, e nem são produzidos num vazio social que garantiria a sua objetividade. São obtidos por meio de uma situação particular de interação social, estruturada, e não somente na relação pesquisador-pesquisado. Entretanto, como em toda situação provocada, é importante levar em consideração o fato de não se ter razão para admitir que o sujeito se submeterá passivamente às recomendações 
do pesquisador e dirá convincentemente a "verdade". Conscientemente ou não, o indivíduo diz só o que pode e quer dizer, fato que é determinado pela representação que faz da situação e por seus objetivos, os quais poderão ou não coincidir com as representações do pesquisador, só podendo o seu discurso serinterpretado na relação com as condições em que foi produzido.

Assim, o questionário consiste em produzir um conjunto de discursos individuais que possam ser interpretados e generalizados.

Buscou-se, portanto, com o questionário, apreender as preocupações dos professores, de forma que pudessem explicitar seus pontos de vista relativamente a temas que se identificam como pertinentes para este estudo. Recorreu-se, ainda, ao questionário para compreender fenômenos como as atitudes, as opiniões, as preferências, as representações, que, de acordo com Ghiglione e Matalon (1997,p. 13), “[...] só são acessíveis de uma forma prática pela linguagem, e que só raramente se exprimem de forma espontânea".

Para melhor compreensão do que pensam e sugerem os professores sobre formação permanente, foram feitas as seguintes perguntas:

a) Você é consultado sobre as dificuldades na prática docente?

b) Sua participação é obrigatória na formação permanente?

c) Os conteúdos da formação permanente são satisfatórios?

d) O que você pensa da formação que recebe?

e) O que você sugere sobre a formação permanente?

f) A participação nos processos de formação tem contribuído para a transformação da sua prática docente?

\section{Análise e discussão dos resultados}

As respostas às referidas questões foram analisadas com o apoio do programa Alceste ${ }^{\circledR}$. Este é um software para análise de dados textuais, cuja metodologia tem a finalidade de filtrar o essencial da mensagem contida em um texto. Para isso, toma como base as leis de distribuição do vocabulário nos textos transcritos ou escritos.

Como recurso auxiliar, optou-se pela análise fatorial por correspondência que permite a visualização das oposições resultantes da classificação hierárquica descendente, a partir da "análise textual" dos conteúdos do questionário, realizada com o apoio do software Alceste ${ }^{\circledR}$. 
O plano fatorial, resultado da "análise fatorial de correspondência" realizada com o apoio do software Alceste ${ }^{\circledR}$, permite - em função da classificação hierárquica descendente - visualizar as posições discursivas opostas, produzindo variáveis suplementares traduzidas do discurso das classes examinadas na fase anterior. Observa-se que o discurso dos sujeitos estrutura-se em diferentes zonas que estabelecem uma correspondência direta com o conteúdo específico de cada classe.

No caso específico desta pesquisa, a projeção do plano fatorial apresenta as palavras analisadas no cruzamento entre os fatores, conforme as variáveis suplementares e a posição do sujeito diante das variáveis, e o que pensa e sugere sobre formação permanente resultantes da análise de conteúdo.

\section{O que pensa e o que sugere sobre formação permanente}

Ao procurar compreender o que pensam e sugerem os professores sobre formação permanente, obteve-se vasta quantidade de informações e indícios de uma variedade de comportamentos de um mesmo indivíduo a respeito do assunto.

As respostas dos professores acerca de formação permanente alternaram-se entre uma posição de resistência a uma posição de flexibilização diante do aspecto cognitivo. Na perspectiva da resistência, o discurso dos professores é de preocupação, no sentido de que a formação seja dinâmica, ajude a melhorar a prática, pois, de modo geral, esses processos formativos deixam a desejar, não traduzem a realidade da escola. $\mathrm{Na}$ perspectiva da flexibilização, o discurso aponta para a necessidade de que melhorem o processo ensino-aprendizagem, sejam direcionadas, haja avaliação, aconteça troca de experiências entre os professores.

Assim, todo confronto de representações sobre a formação, supostamente favorece a tomada de consciência dos professores, mas, ao mesmo tempo, percebe-se que cada um estima que, aquilo que lhe parece o próprio bom senso não se transfere de si para outro. Para esses professores, a formação permanente aparece como uma alternativa de melhoria e desenvolvimento da sua prática pedagógica e como um meio de autovalorização (pessoal). Daí sugerirem formações permanentes que atendam às questões do dia a dia e de seu desenvolvimento cognitivo. Ressalta-se não ser válida apenas uma prática pedagógica contextualizada 
de formação permanente, mas é preciso, também, fortalecer a autonomia do professor no sentido da construção da identidade docente.

Logo, a identidade materializa-se no ponto de vista que o sujeito tem do seu valor e do poder sobre si mesmo, sobre os outros e os acontecimentos. O sentimento de rejeição, desvalorização, privação de poder pelo grupo social pode atingira identidade pessoal em suas dimensões de valor, podere autonomia.

\section{Considerações finais}

As contribuições aqui apresentadas apontam e confirmam que a busca pela formação é exigência dos tempos atuais e não se pode mais admitir que não privilegie a construção da autonomia intelectual do professor, também, indicam que a revalorização da formação de professores seja vista não só como eixo estratégico do desenvolvimento das reformas educativas, mas também como instrumento de gestão das carreiras e das práticas educativas.

Como se pode observar, os resultados apontam para a necessidade de formação e da consideração dos professores como sujeitos ativos desse processo de construção e de desenvolvimento pessoal e profissional. O processo de formação nos contextos de trabalho é apontado como a oportunidade de uma nova maneira de os professores viverem a profissão, refletindo e agindo para que, coletivamente, possam produzir mudanças significativas em suas práticas.

Nos dias atuais, a teoria das representações sociais no campo educacional tem seu lugar de destaque, pois é uma forma de conhecimento prático, social, que orienta as ações, aproximando-as das reais necessidades dos indivíduos. Este estudo indica que no cerne das representações sociais de formação permanente reside a necessidade de aprimoramento constante e a busca pelo reconhecimento e valorização profissional e pessoal do professor.

Os conceitos de representação social dão ênfase ao cognitivo, emocional e atitudinal dos professores que vivem e convivem em sociedade, sempre contextualizando em relação aos saberes, conhecimentos da sociedade contemporânea, dentro de um período histórico, respeitando todo o desenvolvimento cultural construído previamente.

As representações sociais são, pois, um misto das ideias e crenças que os professores acumularam sobre o trabalho que desenvolvem e a formação permanente que buscam e que recebem, associam-se ao sentimento e à 
consciência de pertencer a um grupo, de ser um profissional que interage com o meio e os outros. Este estudo vem, portanto, confirmar a relevância da teoria das representações sociais como ferramenta apropriada para se compreender os objetos educacionais como um todo e a formação dos docentes em particular.

\section{Referências}

AMIGUINHO, A. J. M. Viver a formação, construir a mudança. Lisboa: Educa, 1992.

CANÁRIO, R. Educação de adultos: um campo e uma problemática. Lisboa: Educa, 1999.

CARAMELO, J.; TEERASÊCA, M.; PACHECO, N. Formar/formar-se que estratégias? In: CONGRESSO INTERNACIONAL DE FORMAÇÃO DE PROFESSORES NOS PAÍSES DE LÍNGUA E EXPRESSÃO PORTUGUESA, 3., 1997, Porto. Texto policopiado... Porto: [s.n.], 1997. p. 1-10.

COELHO, N. N. Literatura: arte, conhecimento e vida. Petrópolis: Vozes, 2000.

ESTEVE, J. M. Mudanças sociais e função docente. In: NÓVOA, A. (Org.). Profissão professor. Porto: Porto, 1995. p. 93-124.

FREIRE, P. Pedagogia da autonomia: saberes necessários à prática educativa. 6. ed. São Paulo: Paz e Terra, 1997.

GHIGLIONER, R.; MATALON, B. O inquérito: teoria e prática. Oeiras: Celta, 1997.

JODELET, D. Reprèsentation sociale: phenomênes, concep et theories. In: MOSCOVICI, S. (Coord.). Psichologie sociale. Paris: PUF, 1984. p. 357-378.

. As representações sociais. Tradução de Lilian Vlup. Rio de Janeiro: Ed. da UERJ, 2001.

LUNA, S. V. de. O falso conflito entre tendências metodológicas. In: FAZENDA, I. C. A. (Org.). Metodologia da pesquisa educacional. 3. ed. São Paulo: Cortez, 1994. p. 23-33.

MAGALHÃES, A. M. Nem todos podem ser doutores?! Porto: Profedições, 2000. 
MOSCOVICI, S. A representação social da psicanálise. Tradução de Álvaro Cabral. Rio de Janeiro: Zahar, 1978.

NÓVOA, A. Os professores - Quem são? Donde vêm? Para onde vão? In: STOER, S. (Org.). Educação, ciências sociais e realidade portuguesa: uma abordagem Pluridisciplinar. Porto: Afrontamento, 1991. p. 59-130.

PACHECO, N. A. Interculturalismo e formação de professores. In: MILICE, S.; ANGELINA, C. (Org.). Interacção cultural e aprendizagem: correspondência escolar e classes de descobertos. Lisboa: Fundação Calouste Gulbenkian, 1997. p. 86-97.

PLACCO, V. M. N.; SILVA, S. H. S. da. A formação do professor: reflexões, desafios e perspectivas. In: CHRISTOV, L. H. da S.; ALMEIDA, L. R. de.; BRUNO, E. B. G. (Org.). O coordenador pedagógico e a formação docente. 3. ed. São Paulo: Loyola, 2002. p. 25-32.

Recebido: 25/05/2009

Received: 05/25/2009

Aprovado: 20/06/2009

Approved: 06/20/2009 